\title{
Percepções de estudantes do ensino fundamental sobre sua avaliação de aprendizagem
}

\author{
Karen Sasaki \\ Fundação Visconde de Cairu (FVC), Bahia - BA \\ Luana da Cruz Portella Oliveira \\ Fundação Visconde de Cairu (FVC), Bahia - BA \\ Maribel Oliveira Barreto \\ Fundação Visconde de Cairu (FVC), Bahia - BA \\ Nívea Maria Fraga Rocha \\ Fundação Visconde de Cairu (FVC), Bahia - BA
}

\begin{abstract}
Resumo
O artigo apresenta a percepção de estudantes do Ensino Fundamental I sobre o processo de avaliação de sua aprendizagem. Realizou-se uma pesquisa qualitativa, com análise de estudo de caso descritivo. A seleção de instrumentos e técnicas de pesquisa incluiu entrevistas semiestruturadas, complemento de frases e mapas mentais. A pesquisa foi desenvolvida em uma escola de Educação Básica privada de Salvador-Bahia, coma participação de onze sujeitos, entre os quais gestores e estudantes com idade entre seis e dez anos. Foi constatado que a escola possui proposta pedagógica humanista e gestores capacitados pedagogicamente, mas os estudantes consideram a avaliação como um instrumento de verificação tradicional com sobrecarga emocional e estressante. A avaliação não é percebida pelos estudantes como um mecanismo processual que integre sua aprendizagem.
\end{abstract}

Palavras-chave: Avaliação, subjetividade, estudantes de ensino fundamental.

\section{Elementary school students'perception towards their evaluation of learning}

\begin{abstract}
The purpose of this study was to investigate elementary school students' perception of the learning evaluation. A qualitative research was used with analysis of descriptive case study. The selection of instruments and research techniques included semi-structured interviews, mind maps and completing sentences. A research was conducted in private school in Salvador, Bahia with participation of 11 subjects, including school managers and students aged between 6 to 10 years. The school has pedagogical humanist and trained managers, but students consider the assessment as a traditional tool of evaluation, stressing and emotional overload. Students do not perceive evaluation as a procedural mechanism that integrates their learning. Keywords: Evaluation, subjectivity, elementary school students.
\end{abstract}

\section{Percepciones de estudiantes de la enseñanza fundamental sobre su evaluación de aprendizaje}

\section{Resumen}

El artículo presenta la percepción de estudiantes de la Enseñanza Fundamental I sobre el proceso de evaluación de su aprendizaje. Se realizó una investigación cualitativa, con análisis de estudio de caso descriptivo. La selección de instrumentos y técnicas de investigación incluyó entrevistas semi-estructuradas, complemento de frases y mapas mentales. La investigación se desarrolló en escuela de educación básica privada en Salvador-Bahía con participación de 11 sujetos, incluyendo gestores y estudiantes con edades entre 6 a 10 años. Se constató que la escuela tiene propuesta pedagógica humanista y gestores capacitados pedagógicamente, sin embargo los estudiantes consideran la evaluación un instrumento de verificación tradicional que genera sobrecarga emocional y estresante. La evaluación no es percibida por los estudiantes como un mecanismo procesal que integra su aprendizaje.

Palabras Clave: Evaluación, subjetividad, estudiantes de primer grado. 


\section{Introdução}

O objetivo deste artigo é analisar a percepção de crianças do Ensino Fundamental I ( $1^{\circ}$ ao $5^{\circ}$ ano), com idade entre 6 e 10 anos, sobre o processo de avaliação de sua aprendizagem durante a rotina educacional de sua vida escolar. Durante a pesquisa buscou-se identificar os elementos que influenciam essa percepção e a concepção de avaliação de aprendizagem desses estudantes, e mapear as práticas e estratégias de avaliação de aprendizagem desenvolvidas na Ananda Escola e Centro de Estudos. Todos os objetivos da pesquisa são contemplados neste artigo.

A opção metodológica foi o Estudo de Caso descritivo com ênfase na análise qualitativa. A aplicação da pesquisa foi feita numa escola privada situada em um bairro periférico da cidade do Salvador-Bahia. Para a coleta de informações foram utilizados três tipos de instrumentos de pesquisa com onze sujeitos: nove estudantes, a diretora da escola e a coordenadora pedagógica.

O artigo está assim estruturado: a primeira seção problematiza a discussão acadêmica sobre a relação estudante-professor e o papel da avaliação como elemento consolidador dessa relação; em seguida, fundamenta-se a construção do conceito de avaliação da aprendizagem pelos estudantes e sua aplicação no Ensino Fundamental; e finalmente se apresenta o estudo de caso realizado na Escola onde se realizou a pesquisa e os resultados da investigação.

\section{Percepções sobre a relação estudante-professor e o papel da avaliação}

Pesquisas que tenham como foco a percepção de estudantes sobre seu processo de avaliação são escassas na literatura brasileira, embora existam estudos consolidados sobre o fracasso escolar (Angelucci, 2004; Bossa, 2000, 2002; Damiani, 2006) e sua relação entre evasão e repetência.

Essa discussão tem relação transversal com temáticas de diferentes ordens, como dificuldades de aprendizagem do estudante, inadequação do estudante às normas escolares, saúde psicológica do estudante e sua relação familiar, estratégias pedagógicas ineficientes e questões sociopolíticas de amplo espectro (Collares, 1996; Machado, 1997; Patto, 1996).

Uma antiga pesquisa conduzida por Davidson e Lang (1960) analisou a percepção de estudantes sobre a interação com o professor e as expectativas dos professores sobre o desempenho acadêmico e o comportamento deles em sala de aula e o processo de ensino e aprendizagem.

Mais recentemente Schiavoni e Martinelli (2005) e Martinelli e Schiavoni (2009) constaram os mesmos resultados encontrados na década de 1960, segundo os quais, quanto maior o nível de dificuldade de aprendizagem dos participantes, menos positiva a percepção que eles têm sobre as expectativas dos professores a seu respeito. Além disso, o fator "comportamento em sala de aula" também é decisivo para a afirmação da percepção do estudante sobre a expectativa do professor - ou seja, se o estudante se autopercebe como "pouco comportado", ele não alimenta expectativas positivas dos professores sobre seu próprio rendimento acadêmico.

Numa análise oposta - a percepção de professores sobre seus estudantes - os estudos de Schiavoni \& Martinelli (2005) relataram que a motivação do professor, sua filosofia e prática educacional e suas estratégias de planejamento pedagógico são menos positivas para os estudantes com menor rendimento acadêmico.

Importa considerar que a relação entre expectativas dos professores e seus efeitos no processo de aprendizagem de seus alunos é objeto de discussões ampliadas, antigas e recentes, além de controvérsias sinalizadas por inadequação metodológica no levantamento de dados de pesquisa e generalização de resultados alcançados (Franco, 2009).

A análise da pesquisa desenvolvida por Collares (1995) é interessante por apresentar professores que no primeiro bimestre do período letivo identificam estudantes que não conseguiriam aprender e/ou seriam reprovados ao final do ano. Os dados revelaram que $94,1 \%$ dos casos foram confirmados de forma "premonitória".

Baseada nos estudos de Pfromm Netto (1987) e Pozo (1996), Boruchovitch (1999) argumenta que as teorias de aprendizagem têm focalizado a interação entre o conteúdo a ser aprendido e os processos psicológicos necessários para aprender, enfatizando as análises sobre o modo pelo qual o estudante adquire, filtra, compreende e transforma a informação.

A atividade docente não pode restringir-se ao processo de ensino e transmissão de conhecimentos, mas deve contemplar também o desenvolvimento dos processos psicológicos pelos quais o conhecimento é adquirido pelo estudante (Pozo, 1996); e para que essa meta educacional seja atendida o processo de avaliação precisa deixar de ser uma das atividades da rotina curricular para tornar-se o centro do processo pedagógico. Afinal, a literatura aponta a necessidade de uma transformação prática no processo de avaliação de aprendizagem em prol de um processo de avaliação contínuo, e não pontual, que tenha como finalidade a orientação da aprendizagem e a verificação das competências adquiridas, e como um meio, e não um fim do processo de ensino-aprendizagem (Esteban, 2001, 2002; Luckesi, 2008; Perrenoud, 1999).

\section{A construção do conceito de avaliação por estudantes do Ensino Fundamental}

As recentes discussões sobre avaliação de aprendizagem sustentam que a avaliação é um meio e está delimitada por uma determinada teoria e uma determinada prática pedagógica (Caldeira, 1997). Consubstanciando essa afirmação, Chueiri (2008) mapeou quatro significados para a prática da avaliação, associando-as às respectivas concepções pedagógicas. 
Para Chueiri (2008), examinar para avaliar é o primeiro significado de avaliação escolar, e resgata as práticas dos séculos $\mathrm{XVI}$ e XVII com as configurações da atividade pedagógica produzidas pelos padres jesuítas. Nesse contexto a pedagogia é tradicional e a avaliação é reduzida a um exame escolar.

O segundo significado, medir para avaliar, remete-se ao início do século XX, quando prevalecaram os testes padronizados para medir habilidades e aptidões dos estudantes, inclusive os testes de inteligência psicométricos de Sperman (1904, 1907, 1913) e Binet e Simon (1905), ambos citados por Chueiri (2008).

Dias Sobrinho (2003, p. 17) sustenta que na segunda dimensão a avaliação escolar se traduz basicamente em "testes de verificação, mensuração e quantificação de resultados", uma vez que a avaliação passa a ser utilizada como medida de desempenho dos estudantes, sem considerar a subjetividade do avaliador. Esse período molda a Pedagogia Tecnicista, que muito contribuiu com a Psicologia Comportamental da aprendizagem.

O terceiro significado da avaliação escolar, avaliar para classificar ou para regular e o diploma/certificado, é o símbolo social que atesta que o seu portador está apto para desenvolver determinadas atividades, enfim, que foi classificado num conjunto de exames que lhe atesta uma formação. É a materialização da "nota", a qual significa fonte de desejo e sofrimento dos estudantes (Chueiri, 2008; Perrenoud, 1999).

Como forma de ruptura das concepções pedagógicas de avaliação denominadas tecnicista e quantitativa, o quarto significado é avaliar para qualificar, em que se discute a concepção qualitativa da avaliação que enfatiza o processo, e não o produto final, considerando a dimensão social da constituição da subjetividade do estudante. Assim, conclui Chueiri (2008, p. 61) que o conceito de avaliar para qualificar "exige que a questão metodológica da avaliação seja tratada com pluralidade e maior flexibilidade, a fim de contemplar as diferenças".

Os Parâmetros Curriculares Nacionais (PCNs) são a principal referência teórico-metodológica da prática pedagógica da educação básica. Assim, a concepção de avaliação proposta pelos PCNs (Brasil, 1997) é contraposta à avaliação tradicional, visto que percebe a primeira como uma peça integrante e intrínseca do processo educacional. Segundo os PCNs, a avaliação, não pode se restringir ao julgamento sobre sucessos ou fracassos do estudante, mas abranger a união de atuações com o papel de nutrir e direcionar a intervenção pedagógica. Deve acontecer "contínua e sistematicamente por meio da interpretação qualitativa do conhecimento construído pelo aluno" (Brasil, 1997, p. 81).

A literatura pedagógica da teoria de Piaget (1982) indica que a avaliação de aprendizagem para estudantes em idade escolar do $1^{\circ}$ ao $5^{\circ}$ ano não é eficiente, porquanto nessa fase eles se encontram no estágio operatório-concreto, em que dependem do mundo concreto para abstrair, por isso necessitam do estudo por comparação. Nesse período são necessárias experiências significativas que estimulem o processo de aprendizagem e construção de conhecimentos, desde quando o conteúdo é apreendido à medida que se relacionam com as concepções prévias ou espontâneas.

O processo de aprendizagem não pode ser avaliado pontualmente, pois o desenvolvimento cognitivo do estudante depende do processo de equilibração, no qual o sujeito constrói o conhecimento em ritmos diferentes. Para que uma avaliação do processo de aprendizagem seja feita de forma eficaz é necessário considerar três fatores. O primeiro é de natureza orgânica, representado pelo estágio de desenvolvimento neurológico do sujeito; o segundo é o de natureza social, e nele os processos de interação e transmissão sociocultural são efetivados com intensidades diferentes; e o último fator é de natureza interacionista, porquanto os sujeitos interagem com sujeitos e objetos para construir novos conhecimentos.

Dessa forma, o processo de equilibração de cada estudante ocorre ciclicamente e de forma variável, de modo que, em alguns casos, as intervenções pedagógicas são transformadas em aprendizagem significativa algum tempo depois de sua aplicação. Nesse contexto, um instrumento avaliativo caracterizado por uma prova ou exame traduz uma situação de aprendizagem momentânea, sem refletir o processo de forma global e contextualizada.

Ao passarem pelo estágio operatório-concreto, os estudantes descobrem-se como pessoas, compreendem o mundo que os rodeia, assim como os fenômenos naturais e sociais e as semelhanças e diferenças nas formas mais abstratas, e fortalecem a relação com a leitura, a escrita e o cálculo. Esse processo Ihes possibilita desenvolver uma visão mais crítica e lógica sobre os acontecimentos (Piaget, 1982).

Por outro lado, o Ensino Fundamental I não pode ser reduzido ao objetivo de saber ler, escrever e contar, nem ao exame periódico trimestral que testará essas capacidades. É necessário compreender as transformações pelas quais passam os estudantes nessa fase da vida, para auxiliá-los no seu desenvolvimento integral.

Assim é imprescindível, no mínimo, diversificar as estratégias de ensino-aprendizagem durante o processo educacional, uma vez que elas potencializam a aprendizagem e permitem que o estudante ultrapasse os limites pessoais e sociais e conquiste mais êxito escolar (Boruchovitch, 1993; Dembo, 1994).

Diante desse cenário, percebe-se a necessidade de refletir, mais que a respeito da validade da avaliação escolar, sobre os mecanismos e as formas de executar a avaliação, o sentido atribuído a ela e as influências que ela exerce na saúde psicológica do estudante do Ensino Fundamental.

\section{Funcionamento do processo de avaliação de ensino-aprendizagem na escola lócus da pesquisa}

A Escola selecionada para realização da pesquisa adota a Teoria das Inteligências Múltiplas de Gardner (1994, $1995,1998)$ como princípio epistemológico para a prática pedagógica da rotina escolar, e se propõe a desenvolver estratégias de ensino-aprendizagem que auxiliem no processo 
de despertar, desenvolver e construir a consciência do ser humano.

No tocante ao processo de avaliação, a Escola mantém equilíbrio entre as teorias pedagógicas anunciadas anteriormente, visto que realiza as tradicionais provas bimestrais, com um diferencial na forma como é utilizada com os estudantes, porque há "[...] resgate do conhecimento dos sujeitos".

Como considera Habermas (1989), esse é um aspecto importante, pois coloca o ser humano no centro do interesse do conhecimento. Afinal, o "resgate" tem o objetivo de fazer da avaliação escrita um momento de aprendizagem, e não um exame tenso e classificatório.

Os estudantes realizam mensalmente atividades de testagem pautadas pelos princípios pedagógicos da caixa piagetiana, material desenvolvido com base nos conceitos matemáticos, a saber: classificação, seriação, sequenciação, comparação e conservação (Piaget, 1982). Tais atividades destinam-se a identificar os estágios da aprendizagem dos estudantes e a melhor maneira de intervir com os estímulos e recursos adequados a cada estudante, considerando o seu desenvolvimento cognitivo.

Focada especialmente na avaliação de aprendizagem, a prática da escola acontece da seguinte forma: os estudantes realizam a avaliação escrita, por disciplina, sem fazer consulta a materiais; em um encontro seguinte, depois de o professor corrigir todas as avaliações da turma, é dada aos estudantes a oportunidade de realizar o "resgate do conhecimento".

No momento do "resgate" os estudantes analisam o que fizeram na avaliação, guiando-se pelos registros escritos do professor, que os orientam sobre como encontrar as respostas corretas nas suas fontes de estudo. Assim, durante toda a aula os estudantes leem as considerações do professor e refazem as questões que eventualmente tenham ficado incompletas e/ou incorretas, com foco exclusivo na aprendizagem dos conteúdos deficitários, porquanto não existe atribuição direta de notas para as questões refeitas.

Com a realização do "resgate" o estudante ganha em dois sentidos: na consolidação do conhecimento e na avaliação qualitativa do professor, que pode ser decisiva para que o estudante alcance a média escolar, que é 7,0 (sete). Cabe esclarecer que nesses registros do professor nas avaliações escritas não existem menções à nota do estudante, embora as notas sejam registradas no diário de classe. $O$ estudante só tem acesso à sua nota por meio do boletim escolar entregue aos pais/responsáveis ou quando pergunta diretamente ao professor, o qual informa oralmente.

Ao final do "resgate" a nota do estudante é atribuída através da análise quantitativa do aproveitamento direto na avaliação escrita, somada a uma análise qualitativa. Esta última é caracterizada pela possibilidade de aumentar a nota do estudante caso o professor perceba melhoria real entre o conhecimento construído inicial e o final.

Além dessa abordagem diferenciada na condução da realização da prova, o professor registra diariamente, em um quadro individual desenvolvido pela coordenação pedagógica, a relação das suficiências e deficiências do estudante nas dimensões social, cognitiva e motora. Com essa análise e um eficaz acompanhamento da coordenação pedagógica, o professor planeja suas aulas buscando sanar as deficiências "diagnosticadas".

O processo de avaliação de aprendizagem conta ainda com a autoavaliação, que ocorre ao final de cada etapa. Nesta autoavaliação os educandos refletem sobre quesitos como pontualidade, assiduidade, organização dos trabaIhos, participação em sala e relacionamento com o professor e amigos, relatando em conversa coletiva o que precisa ser melhorado para a próxima etapa (bimestre). Esse momento de autoavaliação contribui para a avaliação qualitativa realizada pelo professor caso haja necessidade e seja justo o eventual aumento de notas.

\section{Método}

A pesquisa foi realizada em uma escola privada, de Ensino Fundamental, situada na cidade do Salvador, Bahia. Fundada em 1996, em 2012 possuía 131 estudantes, sendo 54 do Ensino Fundamental 1, e nove docentes, que, além de facilitar o processo de ensino-aprendizagem ,também atuavam como responsáveis pelos núcleos de formação e capacitação pedagógica, os quais se dedicam ao estudo das seguintes temáticas: Artes, Alfabetização, Consciência, Criatividade, Genialidade, Inteligência, Língua Portuguesa, Lúdico e Psicomotricidade. Os núcleos atuam como centros de formação pedagógica continuada do corpo docente e são abertos à sociedade em geral (estudantes, pesquisadores e afins).

Para atender aos objetivos propostos foi adotado o Estudo de Caso Descritivo (Stake, 2007; Yin, 2003), com ênfase na análise qualitativa e embasada em González Rey (2005a, 2005b). Tal escolha deveu-se ao fato de esse tipo de investigação distinguir-se pela sua ênfase no tratamento holístico dos fenômenos e possibilitar interpretação da realidade em processo contínuo de construção e refinamento. É importante entender que cada sujeito partícipe da pesquisa foi compreendido como um microcaso que favorece a composição do macroestudo de caso.

\section{Sujeitos}

Esta pesquisa contou com a participação de onze sujeitos, a saber, nove estudantes do Ensino Fundamental $\left(1^{\circ}\right.$ ao $5^{\circ}$ ano) da faixa etária de 6 a 10 anos (seis do sexo feminino três do sexo masculino), a diretora da escola e a coordenadora pedagógica desse nível de ensino.

Todos os estudantes estudam nessa escola pelo menos há três anos; a diretora e a coordenadora pedagógica são fundadoras da Escola e possuem graduação em pedagogia e pós-graduação lato sensu específica da área de educação e formação de professores. Tal caracterização do público partícipe da pesquisa possibilita uma melhor compreensão da prática de avaliação de aprendizagem da escola. 
Os estudantes sujeitos da pesquisa não foram caracterizados individualmente por decisão das pesquisadoras, com o intuito de manter em sigilo as suas identidades. A garantia do anonimato foi fator decisivo para a participação dos estudantes de uma forma mais sincera e livre, uma vez que eles mesmos ficaram inicialmente receosos de que seus pais descobrissem o que eles falariam durante a pesquisa.

Em atendimento à Resolução $n^{\circ} 196$ do Conselho Nacional de Saúde 196, o Termo de Consentimento Livre e Esclarecido foi assinado pelos pais ou responsáveis legais dos estudantes, assinatura que foi adotada como critério para a participação dos estudantes na pesquisa. O termo foi enviado para a residência dos estudantes juntamente com um material explicativo sobre a pesquisa, seus objetivos e método de realização. A assinatura do Termo autorizou a gravação em áudio de todos os momentos, resguardando-se a identificação. Evidentemente, foi facultado a todos os estudantes desistir da participação da pesquisa em qualquer momento ou deixar de fornecer informações que eles julgassem inadequadas ou inconvenientes.

\section{Instrumentos de coleta de dados/Informações}

Considerando os constructos teóricos que norteiam a abordagem da epistemologia qualitativa os instrumentos de geração de informações combinaram análises individuais com diferentes formas livres de expressão.

Entende-se que cada instrumento representa apenas o meio pelo qual se procura provocar a expressão do outro sujeito, apoia-se em expressões simbólicas diferenciadas das pessoas e faz parte de um sistema pelo qual os sujeitos e as subjetividades interagem, dando origem a um único sistema de informação (González Rey, 2005a).

Assim, a geração de informações durante a pesquisa se deu através dos seguintes instrumentos: 1- entrevista semiestruturada (ES) com todos os sujeitos (direção, coordenação pedagógica e estudantes); 2- complemento de frases (CF), somente com estudantes do $3^{\circ}$ ao $5^{\circ}$ ano; e 3- mapa mental (MM), somente com estudantes do $1^{\circ}$ e $2^{\circ}$ anos.

\section{Procedimentos de coleta de dados/informações}

A pesquisa foi estruturada em quatro fases, com a utilização de três instrumentos de pesquisa aplicados individualmente. Na primeira fase foi desenvolvido um projeto da pesquisa que foi apresentado formalmente pelas pesquisadoras à diretora da escola, para esclarecimentos e pedido de autorização para realizar a pesquisa.

Após a aprovação da direção da escola para realizar a pesquisa, foi agendada reunião para a realização de entrevista semiestruturada com a diretora, para compreensão das bases teórico-práticas do processo de avaliação de aprendizagem da escola. Em outra data agendada foi realizada a entrevista semiestruturada com a coordenadora pedagógica do Ensino Fundamental I, para apresentação e contextualização do funcionamento das ações de avaliação do processo educacional da escola.

Após entendimento da direção da escola sobre a metodologia e os instrumentos de pesquisa que seriam adotados, foi feita a divulgação interna junto às professoras do Ensino Fundamental I, com a solicitação de apoio para distribuição de um resumo do projeto de pesquisa e uma cópia do Termo de Consentimento Livre e Esclarecido nas agendas escolares de todos os estudantes matriculados.

A esses documentos foi anexado um bilhete redigido de próprio punho pelas professoras para ser lido e, caso os pais ou responsáveis legais permitissem a participação do estudante na pesquisa, este o devolvesse devidamente assinado. As pesquisadoras estabeleceram um prazo de vinte dias para devolução dos termos assinados e disponibilizaram e-mail pessoal e telefone para sanar dúvidas dos pais ou responsáveis legais. Esse tempo de resposta dos pais definiu o número de participantes da pesquisa.

A segunda fase deu-se com a realização de um pré-teste dos instrumentos desenvolvidos com estudantes da mesma faixa etária de outra escola de Educação Básica, o qual proporcionou às pesquisadoras a percepção quanto à melhor maneira de abordar as temáticas dos instrumentos com estudantes desse nível de ensino, tendo em vista suas necessidades e o cuidado que demandam no momento da aplicação.

Durante a terceira fase foram realizadas as entrevistas com os estudantes autorizados por seus responsáveis legais, após as quais se solicitava a construção do mapa mental ou a complementação de frases, a depender do ano escolar. Todos os encontros com os sujeitos da pesquisa foram realizados nas dependências da escola, em horário que não prejudicasse sua frequência ou rendimento escolar. As crianças foram entrevistadas em salas de aula vazias ou no espaço da ludoteca, sempre de forma que cada criança ficasse sozinha com as pesquisadoras.

Os dias e horários das entrevistas e aplicação dos instrumentos foram agendados com as professoras responsáveis por cada série. Cada entrevista durou, em média, trinta minutos, porque dependia da tolerância e do poder de concentração de cada estudante. Os mais jovens não conseguiam ficar falando sobre o assunto durante todo o tempo, enquanto os mais velhos tinham paciência para dialogar sobre o assunto de forma mais detalhada.

Com os estudantes do $1^{\circ}$ e $2^{\circ}$ anos foi utilizado o mapa mental. As pesquisadoras solicitavam que os estudantes desenhassem, numa folha de papel em branco, sem pauta e sem molduras, como se sentiam no momento ou no dia da avaliação. O mapa mental foi escolhido numa tentativa de compreender o mundo do estudante a partir do olhar daquele que nele vive através de uma atividade lúdica, uma vez que a imagem transformada em desenho fornece informações sobre como o sujeito percebe e vivencia a avaliação de aprendizagem (Swan, 1997).

Com os estudantes do $3^{\circ}$ ao $5^{\circ}$ anos foi aplicada a complementação de frases, composta por 72 indutores de frases curtos, que "promovem a exposição rápida do sentido 
subjetivo individual que o sujeito atribui ao tema de pesquisa em questão" (González Rey, 2005b, p. 57). Esses indutores tinham foco nas ações de avaliação e mesclavam frases sobre sentimentos, família, escola e dedicação aos estudos escolares. Sua aplicação foi associada a um jogo lúdico no qual as pesquisadoras perguntavam e eles respondiam com rapidez, facultando-se ao estudante pular para próxima frase e voltar a respondê-la depois.

A entrevista realizada com todos os estudantes teve foco na percepção sobre o processo de avaliação de aprendizagem e foi considerada um momento propício para a expressão da subjetividade individual dos sujeitos da pesquisa (González Rey, 2005b). Para interpretação dessas entrevistas foi utilizada a técnica de análise de conteúdo, com o objetivo de realizar a leitura das entrelinhas expressas pelos sujeitos de pesquisa (Lakatos \& Marconi, 2010).

Todas elas só começaram a ser realizadas com total entendimento dos sujeitos sobre a pesquisa e a apresentação pessoal da entrevistadora, que, em alguns casos, contou com a colaboração da professora da turma. É importante dizer que nos sujeitos do $1^{\circ}$ ano a formalidade da entrevista gerou inibição. Assim, para geração das informações necessárias, a professora da turma foi convidada a participar como ouvinte da entrevista, para dar mais segurança ao estudante, e enquanto este construía o mapa mental, as pesquisadoras conseguiram as informações necessárias numa conversa informal.

Durante a quarta fase, as informações geradas através dos instrumentos foram analisadas e categorizadas, para conclusão da pesquisa. Para desfecho foi agendada uma reunião com a direção e a coordenação pedagógica da escola para a entrega de um relatório da pesquisa com as informações geradas e para agradecimentos. O relatório, além de sintetizar os resultados da pesquisa, registrou contribuições às reflexões sobre o processo de avaliação de aprendizagem que são realizadas no âmbito das ações de planejamento pedagógico.

\section{Resultados}

As informações geradas pela pesquisa foram organizadas em três categorias de análise, de acordo com os objetivos da pesquisa: (a) elementos que influenciam a percepção do processo de avaliação de aprendizagem por parte dos educandos; (b) elementos que influenciam na construção da concepção sobre a avaliação de aprendizagem; (c) as práticas e estratégias de avaliação de aprendizagem voltadas para o Ensino Fundamental. Para ilustrar as dimensões citadas serão apresentados trechos de informações geradas pelos instrumentos.

Ao analisarem-se os elementos que influenciam a percepção dos estudantes sobre o processo de avaliação de aprendizagem, observou-se que a tensão e a ansiedade são constantes tanto na situação de avaliação quanto com no tocante ao atendimento às expectativas geradas pelos pais.
São apresentados, a seguir, alguns depoimentos dos estudantes quanto às sensações geradas no dia da avaliação escrita:

No dia da avaliação fico bem nervosa (estudante do $5^{\circ}$ ano - 10 anos).

No dia fico nervoso, com medo de não dar certo (estudante do $3^{\circ}$ ano -8 anos).

Me sinto meio triste [...] (estudante do $1^{\circ}$ ano -6 anos).

Fico nervoso no dia de avaliação [...] quando termino, sinto um alívio [...]. Quando esqueço um assunto na hora da avaliação fico muito nervosa. (estudante do $4^{\circ}$ ano - 9 anos).

O dia de avaliação é agoniante [...] no dia de avaliação fico suando [...] sofro quando faço avaliação (estudante do $4^{\circ}$ ano -9 anos).

Seguem-se alguns depoimentos das crianças sobre a reação dos pais diante do boletim escolar:

Se a nota for ruim, eles brigam. Não sei por que agem assim (estudante do $3^{\circ}$ ano - 8 anos)

É minha mãe que olha minhas notas. Se a nota for boa, ela me dá direitos, se for ruim, ela tira os direitos (estudante do $1^{\circ}$ ano -6 anos).

Se a nota for boa, minha mãe diz: "muito bem". Se for ruim: "não gostei disso" (estudante do $1^{\circ}$ ano - 6 anos).

No dia de receber o boletim fico angustiada (estudante do $5^{\circ}$ ano - 10 anos).

No dia de receber o boletim fico ansiosa (estudante do $4^{\circ}$ ano - 9 anos).

Observa-se que não houve qualquer menção a punições físicas ou castigos por baixo rendimento escolar, mas somente reclamações orais e estímulo verbal para melhoria das notas.

Quanto aos elementos que influenciam na construção da concepção sobre a avaliação de aprendizagem, verificou-se que noção de exame escolar ainda é muito forte na cultura escolar. Além disso, o estudo é reconhecido por todos eles como uma atividade importante para a vida.

Outros depoimentos destacam as ideias que limitam o processo de avaliação, à prova:

A avaliação é uma prova (estudante do $5^{\circ}$ ano - 10 anos).

A avaliação é [...] não sei bem, prova ou atividade (estudante do $3^{\circ}$ ano -8 anos). 
É uma atividade que a gente faz sozinho sem ninguém poder ajudar (estudante do $1^{\circ}$ ano -6 anos).

É uma atividade que se faz sozinho (estudante do $1^{\circ}$ ano - 6 anos).

É quando testamos o conhecimento, o que aprendemos (estudante do $5^{\circ}$ ano, 10 anos)

Foram ricos os depoimentos sobre a importância de estudar:

Estudar é importante. É bom aprender a ler e escrever [...] quando se está perdido, saber ler o mapa e se achar é ótimo. Gosto de estudar às vezes. Às vezes é chato, tipo em História [...] (estudante do $3^{\circ}$ ano -8 anos).

Estudar é muito importante. Eu gosto de estudar, mas não sei o por quê (estudante do $1^{\circ}$ ano -6 anos).

É importante e eu gosto de estudar. Porque sim (estudante do $1^{\circ}$ ano -6 anos)

Estudar é importante, pois todo mundo precisa se educar e o estudo faz parte da educação. Gosto de estudar, porque sempre quero aprender. (estudante do $5^{\circ}$ ano - 10 anos).

Em relação às práticas e estratégias de avaliação do processo de aprendizagem referentes ao Ensino Fundamental, destaca-se:

- Quando a Avaliação se torna interessante:

Gosto da avaliação de Ciências, porque é mais fácil (estudante do $5^{\circ}$ ano - 10 anos).

Às vezes gosto de fazer avaliação, não gosto muito porque dá trabalho (estudante do $3^{\circ}$ ano - 8 anos).

Eu gostaria que a avaliação fosse fácil (estudante do $4^{\circ}$ ano - 9 anos).

- Quanto à competição entre notas:

Quando os colegas perguntam sobre minhas notas eu enrolo [...]. Quando alguém entrega a avaliação antes de mim, faço mais rápido (estudante do $5^{\circ}$ ano - 10 anos).

Quando os colegas perguntam sobre minhas notas eu não digo. (estudante do $4^{\circ}$ ano -9 anos).

Fico alegre quando tenho nota alta [...]. Quando sou a última a entregar a avaliação, fico triste (estudante do $1^{\circ}$ ano -6 anos).

\section{Análise e discussão}

Em decorrência da prática enraizada historicamente em nossa sociedade, a avaliação tornou-se um momento que gera no indivíduo desconforto, tensão, medo e angústia, e acentua uma conduta competitiva. Essa maneira de avaliar é reflexo tanto das estratégias avaliativas que se reduzam a questões de múltipla escolha, quanto da maneira de querer medir uma única resposta de um estudante, sem considerar "todo" o seu processo de construção.

A expectativa inicial das pesquisadoras era que o clima em torno da avaliação fosse ameno ou que a tensão em data prévia fosse minimizada em função da filosofia da escola e da estratégia do "resgate do conhecimento" e da dimensão qualitativa do processo de avaliação; porém, embora a metodologia de avaliação de aprendizagem demonstre preocupação com o desenvolvimento da criança, não fomente a divulgação de notas entre colegas, tampouco faça uma classificação dos "melhores estudantes" por meio de notas, existe uma atmosfera de tensão e competitividade que ronda o processo avaliativo de igual forma em todos os anos do Ensino Fundamental I.

A diretora da escola e a coordenadora pedagógica demonstraram clareza e domínio teórico da literatura pedagógica referente à discussão sobre o processo de avaliação, declarando que a avaliação não pode se restringir à aplicação de um instrumento numa determinada data, mas sobretudo, deve ser um processo no qual o estudante aceite participar ativamente da ação educativa de forma consciente e crítica do seu papel enquanto sujeito inserido num grupo.

É de entendimento das gestoras da escola que não se avalia para classificar estudantes, tampouco para estigmatizar, amedrontar, muito menos para se castigar psicologicamente. Ainda assim, quando os estudantes vivem os momentos da avaliação, demonstraram passar por sentimentos de ansiedade, medo e outras emoções estressantes, que estiveram presentes em todos os sujeitos pesquisados. Esses sentimentos refletem a percepção negativa que possuem sobre a realização de uma avaliação, ainda que eles participem de um contexto pedagógico de acolhimento, diálogo e humanização.

Para os mais jovens, a tensão maior é "fazer uma atividade sozinho(a)", como relatou uma criança do $1^{\circ}$ ano. Para as crianças do $4^{\circ}$ e $5^{\circ}$ anos, o momento da avaliação é percebido quando a professora fica supervisionando a turma, para não haver consultas paralelas. A professora atenciosa e dedicada transforma-se num agente regulador de conduta, exigindo a realização da prova de forma individual e sem consulta a livros ou colegas de classe.

Um momento que chama a atenção é aquele em que os primeiros colegas começam a entregar a avaliação. A pesquisa revelou que isso desencadeia um processo pessoal de geração de dúvidas sobre seu processo de autoaprendizagem e velocidade para realização das proposições avaliativas. Esse processo levanta dúvidas sobre a dificuldade pessoal de cada um no andamento da própria avaliação e tende a aumentar a tensão. Para os estudantes do Ensino 
Fundamental que participaram da pesquisa, a prova é "boa" quando é "fácil" e por isso se faz "rápido". Não houve a associação entre a velocidade ou grau de dificuldade teórica para realização da prova e o nível de aprendizagem do conteúdo que está sendo avaliado.

Há ainda a dimensão do relacionamento com os pais, que pode ser traduzido como o propulsor da geração de medo, porquanto as crianças tendem a se cobrar bom desempenho para atender às expectativas dos progenitores. Isso acarreta outro tipo de associação, expresso pelos estudantes ao relatarem seu relacionamento familiar. Para os estudantes, os pais apreciam o resultado e Ihes dedicam atenção e elogios somente quando eles atingem bons resultados nas avaliações, sem compreender que o processo avaliativo nesse nível de ensino não se restringe à nota de um instrumento de avaliação, que geralmente são provas.

Luckesi (2008), ao traçar as características de uma avaliação com caráter de prova ou exame, lista os possíveis motivos desse comportamento, a saber: o exame tem por objetivo julgar e, consequentemente, aprovar ou reprovar o estudante; o exame é pontual, porquanto o estudante deve saber a resposta das questões no momento das provas e testes, no aqui e agora; o exame é classificatório; o exame é seletivo, na medida em que exclui aquele "que não sabe"; e o exame dá fundamento a uma prática pedagógica autoritária, uma vez que se torna um instrumento de poder.

Uma análise a partir desse ângulo já resultaria nas manifestações comportamentais observadas nos sujeitos da pesquisa, porquanto:

- $\quad$ quando julgados, os sujeitos alimentam em si a ansiedade pela aprovação e o medo da reprovação, fazendo do aprendizado um processo estressante e não prazeroso;

- o momento do exame gera a expectativa de, principalmente, memorizar todo o conhecimento possível, para obter as respostas que serão cobradas nas questões e, consequentemente, de não esquecê-las;

- a partir do momento em que o exame classifica, traça o padrão do que é o melhor e do que é o pior, ele gera nos indivíduos uma inevitável competitividade;

- à medida que exclui os indivíduos que não atingem o padrão determinado, a prova causa repulsão pelos estudos por parte de quem se sente incapaz de alcançar tal padrão;

- se a prática pedagógica é autoritária, o estudante tende a desmotivar-se pelo estudo e pelo ambiente escolar.

Importante considerar também que a prova se torna agradável para os estudantes quando eles têm facilidade em compreender as questões e afinidade com seus professores. O estudo é o elemento central do processo de avaliação e é compreendido como fator importante, mas sem aprofundamento. Percebe-se que há um discurso reproduzido pelos pais, uma vez que os estudantes não expressam com propriedade as justificativas para a continuidade dos estudos.

\section{Conclusão}

As experiências relatadas por educadores e coordenadores de escolas brasileiras já demonstram que a prática da prova tem se tornado obsoleta, e existem tentativas de modificar esse sistema classificatório e excludente ao qual a sociedade esteve submissa durante tanto tempo. Não obstante, o que tem sido verificado é que a avaliação ainda é realizada nos moldes da educação tradicional, a qual valoriza a memorização dos conteúdos e o acúmulo de conhecimentos quase sempre sem nexos com a vida.

Com a realização da presente pesquisa registrou-se que o processo de avaliação "agradável" está associado à situação de o estudante conseguir aprender o conteúdo da disciplina e assim obter melhor desenvoltura para realizar a prova, em termos de tempo de realização da avaliação e de garantia de sucesso. Por outro lado, torna-se desagradável em relação à sobrecarga emocional depositada pelos pais e ao dilema psicológico no atendimento às expectativas deles, porquanto sabem que, caso a meta seja atingida, a nota alta reverte-se em recompensas como acesso ao videogame, presentes e televisão.

Constatou-se que, mesmo que a escola tenha uma proposta pedagógica diferenciada, que os educadores tenham formação continuada e que exista preocupação da coordenação pedagógica em desenvolver um projeto de avaliação pautado por princípios pedagógicos consolidados, a cultura social e a expectativa dos pais continuam transformando a avaliação numa atividade que gera desconforto e estresse.

Assim, impõe-se ao contexto escolar e a todos os sujeitos envolvidos no processo de aprendizagem o desafio de desenvolver uma avaliação que tenha, cada vez mais, a colaboração da família dos estudantes com foco na compreensão coletiva da importância da construção e reconstrução de conhecimentos intelectivos e humanos.

\section{Referências}

Angelucci, C. B. e cols. (2004). O estado da arte da pesquisa sobre o fracasso escolar (1991-2002). Revista Educação e Pesquisa, $30(1), 51-72$.

Boruchovitch, E. (1993). A Psicologia cognitiva e a metacognição: novas perspectivas para o fracasso escolar brasileiro. Revista Tecnologia Educacional, 22(110/111), 22-28.

Boruchovitch, E. (1999). Estratégias de aprendizagem e desempenho escolar: considerações para a prática educacional. Revista 
Psicologia Reflexão e Crítica, 12(2), 135-142.

Bossa, N. (2000). Fracasso escolar: um sintoma da contemporaneidade revelando a singularidade. Tese de Doutorado, Faculdade de Educação da Universidade de São Paulo, São Paulo.

Bossa, N. (2002). Fracasso escolar: um olhar psicopedagógico. Porto Alegre: Artmed.

Caldeira, A. M. S (1997). Avaliação e processo de ensinoaprendizagem. Revista Presença Pedagógica, 3(1), 53-61.

Chueiri, M. S. F. (2008) Concepções sobre a avaliação escolar. Revista Estudos em Avaliação Educacional, 19(39), 49-64.

Collares, C. A. L. (1995). O cotidiano escolar patologizado: espaço de preconceitos e práticas cristalizadas. Tese de Livre Docência, Faculdade de Educação, Departamento de Psicologia Educacional, Universidade Estadual de Campinas, Campinas, SP.

Collares, C. A. L. (1996). Ajudando a desmistificar o fracasso escolar. Em C. A. L. Collares \& M. A. Moysés (Org.), Preconceito no cotidiano escolar - ensino e medicalização (pp. 24-28). São Paulo/ Campinas: Cortez/Unicamp.

Damiani, M. F. (2006). Discurso pedagógico e fracasso escolar. Revista Ensaio: avaliação e políticas públicas educacionais, 14(53), 457-478.

Davidson, H. H., \& Lang. G. (1960). Children's perceptions of their teachers' feelings toward them related to self-perception, school achievement and behavior. The Journal of Experimental Education, 29(2), 107-118.

Dembo, M. H. (1994). Applying educational psychology (5a ed). New York: Longman.

Dias Sobrinho, J. (2003). Avaliação: políticas e reformas da educação superior. São Paulo: Cortez.

Esteban, M. T. (2001). O que sabe quem erra? Reflexões sobre avaliação e fracasso escolar. Rio de Janeiro: DP\&A Editora.

Esteban, M. T. (2002). A avaliação no processo ensino-aprendizagem: os desafios postos pelas múltiplas faces do cotidiano. Revista Brasileira de Educação, 19(1), 129-137.

Franco, A. F. (2009). O mito da autoestima na aprendizagem escolar. Revista Semestral da Associação Brasileira de Psicologia Escolar e Educacional, 13(2), 325-332.

Gardner, H. (1994). Estruturas da mente: a teoria das inteligências múltiplas. Porto Alegre: Artmed.

Gardner, H. (1995). Inteligências múltiplas: a teoria na prática. Porto Alegre: Artmed.
Gardner, H. (1998). Inteligência: múltiplas perspectivas. Porto Alegre: Artmed.

González Rey, F. (2005a). Pesquisa qualitativa e subjetividade: os processos de construção da informação. São Paulo: Pioneira Thomson Learning

González Rey, F. (2005b). Subjetividade, complexidade e pesquisa. São Paulo: Pioneira Thomson Learning.

Habermas, J. (1989). Teoria de la Acción Comunicativa. Madrid, Taurus.

Lakatos, E. M., \& Marconi, M. A. (2010). Fundamentos de metodologia cientifica (7a. ed.). São Paulo: Atlas.

Luckesi, C. (2008). Avaliação da aprendizagem escolar (19a. ed.). São Paulo: Cortez.

Machado, A. M. (1997). Avaliação e fracasso: a produção coletiva do fracasso escolar. Em J. G. Aquino (Org.), Erro e fracasso na escola: alternativas teóricas e práticas (pp. 73-90). São Paulo: Summus.

Martinelli, S. C., \& Schiavoni, A. (2009). Percepção do aluno sobre sua interação com o professor e status sociométrico. Revista Estudos de Psicologia, 26(3), 327-336.

Patto, M. H. S (1996). A produção do fracasso escolar: histórias de submissão e rebeldia. São Paulo: T. A. Queirós.

Perrenoud, P. (1999). Avaliação: da excelência à regulação das aprendizagens. Porto Alegre: Artmed.

Pfromm Netto, S. (1987). A aprendizagem como processamento da informação. Em S. Pfromm Netto (Org.), Psicologia da aprendizagem e do ensino (pp.79-109). São Paulo: EPU.

Piaget, J. (1982). O nascimento da inteligência na criança (4a. ed.). Rio de Janeiro: Zahar.

Pozo, J. (1996). Estratégias de Aprendizagem. Em C. Coll, J. Palácios \& A. Marchesi (Org.), Desenvolvimento psicológico e educação: psicologia da educação (pp. 176-197). Porto Alegre: Artes Médicas.

Schiavoni, A., \& Martinelli, S. C. (2005). Percepção de alunos sobre as expectativas do professor acerca do seu desempenho: um estudo comparativo entre alunos com e sem dificuldades de aprendizagem. Revista Interação em Psicologia, 9(2), 311-319.

Secretaria de Educação Fundamental. (1997). Parâmetros curriculares nacionais. Brasília: MEC.

Stake, R. E. (2007). A arte da investigação com estudos de caso. Lisboa, Portugal: Fundação Calouste Gulbenkian. 
Swan, J. (1997). Using cognitive mapping in management research: decisions about technical innovation. British Journal of Management, 8(2), 183-198.
YIN, R. K. (2003). Estudo de caso. Porto Alegre: Bookman.

Recebido em: 17/07/2012

Reformulado em: 07/02/2013

Aprovado em: 29/04/2013

\section{Sobre as autoras}

Karen Sasaki (ksasaki@terra.com.br)

Fundação Visconde de Cairu (FVC)

Doutora em Desenvolvimento Regional e Urbano. Mestre em Análise Regional. Bacharel em Ciências Sociais com toda a formação acadêmica cursada na Universidade Salvador (UNIFACS). Docente do Mestrado em Desenvolvimento Humano e Responsabilidade Social da Fundação Visconde de Cairu (FVC).

Luana da Cruz Portella Oliveira (profaluana@gmail.com)

Fundação Visconde de Cairu (FVC)

Licenciada em Pedagogia pelo Instituto Superior de Educação Ocidemnte (ISEO). Possui experiência docente nos anos iniciais do Ensino Fundamental em Instituições Privadas. Coordenadora do Núcleo de Pesquisa sobre Conscienciologia da Ananda - Escola e Centro de Estudos.

Maribel Oliveira Barreto (maribelbarreto@terra.com.br)

Fundação Visconde de Cairu (FVC)

Pós-doutora em Educação - Universidade de Brasília (UNB). Doutora em Educação - Universidade Federal da Bahia (UFBA). Mestre em Educação - UFBA. Licenciada em Pedagogia - Universidade Católica de Salvador (UCSAL). Consultora em Ciências da Educação e Pesquisadora da temática "Consciência". Avaliadora ad hoc do Instituto Nacional de Estudos e Pesquisas Educacionais Anísio Teixeira (INEP). Docente do Curso de Pedagogia e Coordenadora do Mestrado Multidisciplinar em Desenvolvimento Humano e Responsabilidade Social - Fundação Visconde de Cairu (FVC).

Nívea Maria Fraga Rocha (niveafragarocha@gmail.com | nivea_rocha@uol.com.br)

Fundação Visconde de Cairu (FVC)

Doutora em Educação - Universidade Autônoma de Barcelona/Espanha. Mestre em Educação - Universidade Federal da Bahia (UFBA). Licenciada em Pedagogia - Centro de Ensino Unificado de Brasília - CEUB. Avaliadora ad hoc do Instituto Nacional de Estudos e Pesquisas Educacionais Anísio Teixeira (INEP). Docente do Curso de Pedagogia e do Mestrado Multidisciplinar em Desenvolvimento Humano e Responsabilidade Social, Fundação Visconde de Cairu (FVC). Professora da Faculdade de Educação - UFBA (aposentada). 